\title{
Interventions of Chinese Nonprofit Charitable Organizations in the Rescue of Children in Difficulty
}

\author{
Yaqiong Du ${ }^{1, *}$ and Lennart Nygren ${ }^{2}$ \\ 1 Department of Humanities and Law, Northeastern University, Shenyang 110169, China \\ 2 Department of Social Work, Umeå University, SE-90187 Umeå, Sweden; lennart.nygren@umu.se \\ * Yaqiong Du:1990dandan2008@163.com; Tel.: +86-18204089792
}

Received: 10 April 2018; Accepted: 9 June 2018; Published: 13 June 2018

check for updates

\begin{abstract}
In June 2016, China promulgated the "Opinions of the State Council on Strengthening the Work of Rescuing Children in Difficulty", which broadened the coverage of child welfare in China. The document clearly encourages and supports the participation of nonprofit charitable organizations in improving and complementing the public support system for children living in difficulty. This paper reports an assessment study of the relief program for children with congenital heart disease, which was launched by the Red Cross in L Province. Semi-structured face-to-face interviews with six Red Cross employees and 10 parents of stricken families, and telephone interviews with 66 recipient families, were carried out. Additionally, a review of a large number of background documents was analyzed to assess interventions by social organizations in the rescue of children in difficulty. The project was shown to reduce poverty and improve medical treatment for children with congenital heart disease. The role of nonprofit charitable organizations in relation to the child protection system can be characterized as "leak-filling".
\end{abstract}

Keywords: children in difficulty (CID); nonprofit charitable organizations; congenital heart disease

\section{Introduction}

In traditional Chinese culture, the idea of collective responsibilities for social welfare was expressed very early. In 551 BC, Confucius, a famous thinker and educator in China, advocated the "benevolence" thought in Confucianism, that is, that life ought to be respected (Confucius about 540 BC-400 BC). During China's thousands of years of history, some traditional values have been advocated, such as respecting the old, cherishing the young, helping the poor, and assisting the needy. In the process of the development of Chinese culture, China's traditional ideas are consistent with today's social work values.

On 29 December 1990, China formally signed the United Nation's Convention on the Rights of the Child (UNCRC). The convention was ratified by the National People's Congress the next year, and entered into force on 1 April 1992. The Convention is a universally applicable standard established by the international community for the protection of children's rights, and the Chinese government undertakes and earnestly implements the obligations stipulated in the convention (State Council 1992). In order to safeguard the child's rights, including the right to subsistence, full development rights, the right to protection from harmful effects, abuse, and exploitation, the right to full participation in the family, cultural, and social life, and so on, the Chinese government continues to formulate and disseminate relevant policies and measures for the implementation of the UNCRC.

\subsection{Organizations and Target Groups}

Professional social work service agencies, charitable organizations, and volunteer service organizations provide professional services related to basic needs, education, health care, rehabilitation, 
and other needs. They also provide funds and materials for the implementation of charitable projects for children in difficulty (State Council 2016). There are various types of social organizations in China that provide relief services for children in difficulty. For example, the Communist Youth League, the National Women's Federation, the China Disabled Persons' Federation, the Chinese Red Cross, and other institutions provide services and care for children's relief. There are various kinds of relief services, corresponding to different circumstances of the children such as financial assistance, medical assistance, spiritual comfort, daily care, and the rehabilitation of children (China Youth Research Center 2006).

In China, children in difficulty (CID) is a concept that has experienced three stages of definition. The wording "children in difficulty" was proposed by the government in 2005, but did not get a clear definition. Between 2005-2010, academics established a definition of the concept based on "vulnerable children": CID includes abandoned babies, orphans, children with disabilities, children in poor areas, children of ethnic minorities, foster children, AIDS orphans, children with criminal families, children with autism, and children forced into child labor (Liu 2005). From 2011 to 2013, the government's use of the concept was clarified, so that the different definitions of CID in government and academia over recent years have been gradually converging. It is generally accepted that CID should include groups of orphans (including abandoned babies), unaccompanied children, street children, children who are victims of violence, children with disabilities, children infected with HIV, and children with a serious or rare illness (Chen 2012). From 2014 until now, the government, academia, and society are in agreement on the definition of CID. The definition includes children who have difficulties due to life circumstances, medical treatment, problems in school, and other aspects of difficulties because of family poverty. Children whose personal safety is threatened or violated due to abuse or neglect from their families, improper custody, abandonment, accidental injury, or unlawful infringement are also included (State Council 2016). More specifically, children's disabilities lead to difficulties that require rehabilitation, care, and programs for social inclusion. Children with congenital heart disease were included in the scope of children with a serious illness. CID contains children with a serious illness, which means that children with congenital heart disease can be classified as CID.

The definition of CID is not applied in Europe and the United States, where the expression "children in need" is a similar concept. As an example, in 2001, the Swedish government revised the Social Services Act, and in accordance with the revised law, a framework for the assessment of child welfare cases was implemented and given the name "children's needs in focus" (National Board of Health and Welfare 2012). In the early 1990s, there was a major reform of the system for assistance for poor children, child abuse prevention, and family adoption in the United States. The promulgation of these bill regulations illustrates the United States (US) government's concern for assistance for poor children and services to children who are in need, and also provides legal protection for the troubled children (Chen 2008).

Nonprofit organizations have an important role in the Chinese social welfare system for children. Such organizations are formed by a group of people in order "to pursue a common not-for-profit goal" (Smith et al. 2006). The sources of funding for China's nonprofit organizations include government finance (the main source), social organizations' support (donations from government organizations and enterprise organizations), membership fees, and donations from related organizations overseas (Liu 2010). An example of a nonprofit charitable organization in China is the Red Cross, which is a social relief group engaged in humanitarian work (National People's Congress Standing Committee Member 2005). The China Red Cross Foundation is a national public body for the funding of social welfare initiatives that has been approved by the Ministry of Civil Affairs; as a nonprofit organization, it is an independent legal entity (Decree of the State Council of the People's Republic of China 2004). The Red Cross Society of China and the China Red Cross Foundation are based on the same purpose: to carry forward the humanitarian, fraternity, and dedication of the Red Cross spirit, and remain committed to protecting people's lives and health. The China Red Cross Foundation raises funds to support the development of the Red Cross mainly through the mobilization of social resources. 
Nonprofit organizations and charitable organizations have different definitions in different locations, and they also play different roles in social functioning, but both are centered on philanthropic goals, as well as social well-being. A handful of examples from different countries illustrates this. Within the Swiss legal framework, only "not-for-profit-making organizations" and "foundations" are defined as legal forms of nonprofit organizations, and as such, are able to provide financial assistance to groups that need help (You 2014). The US government appears to be gradually fading out of the leading role in providing social welfare; it has been increasingly relying on nonprofit organizations to tackle difficult social problems (Li et al. 2012). In November 1998, the central government of Britain and the charity and community center signed The Compact on Relations between Government and the Voluntary and Community Sector, making Britain the first country in the world to sign a compact with nonprofit organizations. Government and nonprofit organizations are functionally complementary: governments gain more resources and save money, and nonprofit organizations are fully financially supported. This cooperation is running well, and Canada and Australia have both taken it as an example and are implementing this method to establish cooperative relationships with their own nonprofit organizations (Shi 2012).

\subsection{The Setting of the Study}

The specific program that is the focus of this paper is the poor children with congenital heart disease (PCHD) relief project. It was initiated by the L Provincial Red Cross in September 2007. All children aged 0-14 with congenital heart disease within the province can be referred to the county (district) level Red Cross, after approval by the provincial Red Cross. Since the end of 2016, the project has successfully rescued 712 children with congenital heart disease. ${ }^{1}$ In the beginning, the project was the responsibility of the provincial Red Cross, for professional considerations; however, the Provincial Red Cross Foundation has managed this project since 2014. The project is mainly funded by the provincial fiscal lottery public welfare fund, and additionally, one part is funded through donations from business enterprises.

The treatment of sick children is provided by two high-standard hospitals in L Province. The two hospitals are state-run not-for-profit hospitals (for ethical reasons, we do not mention the names of the hospitals). They agree with the idea of the Red Cross (humanitarian, fraternity, and dedication), adhere to the spirit of public welfare dedication, and provide surgery for children with cost relief and regular follow-up. The Red Cross and its effects in the relief of CID can to some extent reflect the more general interventions of Chinese nonprofit charitable organizations in the child protection system.

Congenital heart disease incidence cannot be overlooked. The prevalence of congenital heart disease is increasing year by year in China. According to estimates, there will be more than 130,000 new cases of congenital heart disease among children every year in China, and the total economic burden of new congenital heart disease is more than 1.6 billion euros per year (Ministry of Health P.R. China 2012). According to the congenital heart disease pediatrician that was interviewed for this study, a small number of those with congenital heart disease have a chance of self-healing before the age of five, but most patients require surgical treatment to correct malformations. With the rapid development of medical technology, surgical results have greatly improved, and at present, most patients can live normally with no affect to their growth and development if they receive timely surgical treatment. Thus, they can expect to have opportunities to qualify for ordinary work and study, and be able to satisfy ordinary life needs.

\subsection{Aim}

This study describes and analyzes the economic, medical, and spiritual support provided by the Red Cross and cooperative hospitals for children with congenital heart disease. It aims to assess and 
evaluate the relief that families and their children with congenital heart disease have received from a program established by the L Provincial Red Cross.

\section{Methods}

\subsection{Sample Selection and Materials}

The sample in the assessment project comprised face-to-face interviews with 16 subjects and telephone interviews with 66 families. At the end of 2016, the total number of rescue projects was 712, out of which $15 \%$ were selected for telephone interviews. Face-to-face respondents include five Red Cross employees, one hospital employee, and 10 parents of stricken families, all of whom participated in semi-structured interviews. Details of the interviews with the parents were included in the total data of the telephone interview.

All of the children in the interviewed families were younger than eight years old. For ethical reasons, children were not interviewed individually. Our acquisition of data on the child's situation (child's body, emotions, etc.) was carried out in the presence of, and with the informed consent of the parents; all of the information came from semi-structured interviews and telephone interviews with parents, and all of the information was ultimately used in the assessment of the total data. The main documentary materials included abstracts of documents that were accessed with permission from the L Province Red Cross, the partner hospital, and the subordinate local Red Cross.

\subsection{Procedure}

The data collection and assessment of this PCHD research project was carried out by three people. A university teacher was responsible for the project's external contacts, and the project was mainly conducted by the first author and another doctoral student. The second author assisted with the final analyses and drafting of the article.

At the beginning of the project, the members of the assessment team read a lot of documents and literature, and then developed a basic assessment framework and an interview questionnaire. We constructed a basic assessment program after several meetings with the person in charge of the project at the Red Cross. According to the results of the discussions between the two sides, we selected the two poorest cities in the designated city and the core cities where the project started as the data collection area. We selected one leader to be in charge of the program, and two other staff members as the primary interviewers. At this time, a fixed interview template had not yet been drafted. We obtained key materials through explorative questions to interviewees and free talk among the staff. A follow-up interview was conducted with a staff member who came from the hospital treating children with congenital heart disease. Based on this, the research group planned the collection of documentary materials, and a family interview questionnaire was gradually drafted. Ten families residing in the three designated cities were randomly selected. We interviewed the recipient family with the guidance of local staff and followed up with interviews with the staff. After the conclusion of the qualitative research data collection, the telephone interview questionnaire was further improved and finalized to a template consisting of nine closed questions and one open question. The basic family situation (location, number of family members, disease category of children) and telephone number were manually entered into the computer, and then automatically dialed by the telephone interview software. Both face-to-face interviews and telephone interviews were audio-recorded as backup.

\subsection{Measurement and Data Analysis}

The measurement of public welfare projects differs from that of commercial projects. There are no core indicators of profit or separate inspection of the size of funds, and the number of relief activities and other quantitative indicators cannot fully explain the support level. Based on the cases of other assessments of nonprofit organizations (NPOs), combined with local features, we developed a new set of assessment criteria. The evaluation content can be divided into three aspects: organizational 
relationship assessment, project process evaluation, and project result evaluation. The first part has four grade indicators, the second part has 12 grade indicators, and the last part has three grade indicators; these indicators are then combined into a final score. For the collected data, we mainly used SPSS for statistical analyses and quantitative assessment.

Recordings of interviews with staff were transcribed verbatim. Two research team members individually read and extracted codes from these transcripts. Afterwards, the two members exchanged views, and they met in a group to discuss the data in order to extract patterns and formulate thematic interview results. Ten copies of the family interview materials were also transcribed verbatim. The contents of the interviews were analyzed in a similar manner as the staff interviews but with a different focus, including the interviewee's expression, the family environment, and the child's mental and physical condition. These data were merged with observations that we made during the interviews, and reflected on in relation to our own personal feelings, which we documented after the interviews in our research logs. Through the analysis of project-related materials and documents, combined with interviews with recipients, we used inductive analysis to draw some qualitative conclusions about the characteristics, methods, and forms of the project that are not suitable for quantification. In the following results section, information from the document analysis is presented that provides a description of the contextual conditions for the relief project, followed by the thematic analysis that emerged from the qualitative analyses of interviews with staff and families.

\section{Results}

\subsection{The Leak-Filling Role of Nonprofit Charitable Organizations}

China's large population is a fundamental and challenging national condition. Thus, the child welfare system is not fully developed. Children who are in difficulty is the focus of the Chinese child welfare system, yet regional cultural differences, economic level gaps, and inequalities can lead to ineffectiveness in the rescue of vulnerable children in some areas. Due to this, charitable relief becomes an important supplement to helping CID.

The welfare policy for congenital heart disease mainly includes basic medical insurance, major disease health care, urban/rural residents' serious illness insurance, and urban/rural medical assistance. In 2015, 8,900,000 impoverished children were included in the two systems of minimum living security and five guarantees in rural areas (this is China's two kinds of rescue policy to ensure the basic livelihood of the poor), accounting for $3.2 \%$ of the total population of children in China. In terms of income, the population varies from 10 to 150 euros per month. In accordance with the requirements of China's National Health Planning Commission, by the end of 2015, the whole country will achieve full coverage of serious medical insurance. From June 2015 to May 2016, some provinces and municipalities issued the policy of rescuing children with serious illness, among which the congenital heart disease with higher incidence was included in the scope of rescue (Chinese Children's Welfare Policy Research Group 2016). In the case of L Province, the reimbursement of treatment costs for urban and rural poor children with congenital heart disease could theoretically reach $70 \%$, but because of the unbalanced economic development in a whole province, the actual reimbursement ratio is lower than that. For some poor families, the remaining $30 \%$ of the expenditure is still difficult to afford. In addition, children with congenital heart disease were covered under the system of serious illness by the Ministry of Health and the Ministry of Civil Affairs until 2010, but the Red Cross congenital heart disease support project was already founded in 2007. Therefore, between 2007-2010, children with congenital heart disease who had not been included in the government's "rescue list" could get help from the Red Cross rescue project. At this point, the Red Cross's support becomes very timely and necessary. Congenital heart disease relief has features that are relatively uncomplicated; single case assistance requires less money, and it is easier to scale operation, so it can become an effective government aid supplement. Depending on the disease and different economic conditions, the funding of poor families has changed over time, as seen in Table 1. 
Table 1. Rescue funding of poor children with congenital heart disease relief project.

\begin{tabular}{|c|c|c|c|}
\hline Year & Age & Disease Category & Funding \\
\hline 2007-2009 & $3-15$ & Simple congenital heart disease ${ }^{2}$ & $\begin{array}{l}\text { Provincial Red Cross pays for } € 900 \text {, } \\
\text { Individual/City Red Cross pays for } € 600\end{array}$ \\
\hline 2010 & $3-15$ & All types of congenital heart disease & $\begin{array}{c}€ 1300-€ 2600 \text { range } \\
\text { (depending on the disease) }\end{array}$ \\
\hline \multirow{2}{*}{2011} & $3-15$ & All types of congenital heart disease & $\begin{array}{c}€ 1300-€ 2600 \text { range } \\
\text { (depending on the disease) }\end{array}$ \\
\hline & $0-14$ & Simple congenital heart disease & $\begin{array}{l}10 \% \text { for quota medical expenses of rescue } \\
\text { category disease, } € 700 \text { maximum }\end{array}$ \\
\hline \multirow{2}{*}{2012} & $3-15$ & All types of congenital heart disease & $\begin{array}{c}€ 2300-€ 3600 \text { range } \\
\text { (depending on the disease) }\end{array}$ \\
\hline & $0-14$ & Simple congenital heart disease & $\begin{array}{l}10 \% \text { for quota medical expenses of rescue } \\
\text { category disease, } € 700 \text { maximum }\end{array}$ \\
\hline \multirow[t]{2}{*}{ 2013-2016 } & $0-14$ & All types of congenital heart disease & $\begin{array}{l}\text { After the government medical } \\
\text { reimbursement, the Provincial Red Cross } \\
\text { fund for } € 1300-€ 2600\end{array}$ \\
\hline & $0-14$ & Simple congenital heart disease & $\begin{array}{l}10 \% \text { for quota medical expenses of rescue } \\
\text { category disease, } € 700 \text { maximum }\end{array}$ \\
\hline
\end{tabular}

\subsection{Poverty Reduction}

It can be seen from the telephone interviews (66 valid) and face-to-face interviews (10 valid) that this program had the effect of reducing poverty. The survey found that before assistance from the Red Cross, the family's total medical expenses were roughly distributed between $€ 650-7500$. The annual incomes of these families ranged between $€ 650-3500$, and these are incomes that usually must cover the daily needs of all family members (three to five persons.) A family may receive the minimum living allowance of $€ 70$ per person per month from the government. In addition to satisfying the basic needs of life, there is no extra money to deal with serious illness. In the case of a family without serious illness, these funds can only meet basic needs, and if a child becomes seriously ill, the family risks facing catastrophic medical expenses. The World Health Organization (WHO) suggests that catastrophic medical spending refers to how in a fair health care system, personal cash health expenditure (out-of-pocket expenditure, OOP) should not seriously affect the individual or family consumption structure, such as forcing individuals or families to reduce necessary expenses such as food, housing, or child education. When the total cash expenditure on personal health expenses exceeds $40 \%$ of the family's non-food consumption expenditure, medical expenses become catastrophic, according to the WHO (WHO and Regional Office for South-East Asia 2009).

The results show that the rescue project is timely: $80.3 \%$ of the parents said that they will take the child to surgery, but the need to save money would lead to delayed operation time, and may result in the best treatment opportunity being missed. Meanwhile, 19.7\% of parents said if there were no funds, they would have to let the child temporarily endure, and that they may give up treatment. Poverty is the biggest dilemma of the family.

After the Red Cross rescue intervention, the family only needs to pay transportation costs, lodging for relatives, and nutritional needs for the child. The following charts indicate the distribution of funding of treatment between self-funding (Figure 1) and funding from the Red Cross (Figure 2).

2 Simple congenital heart disease means simple and easily cured types of heart disease, while "all types" also include complex congenital heart diseases. 


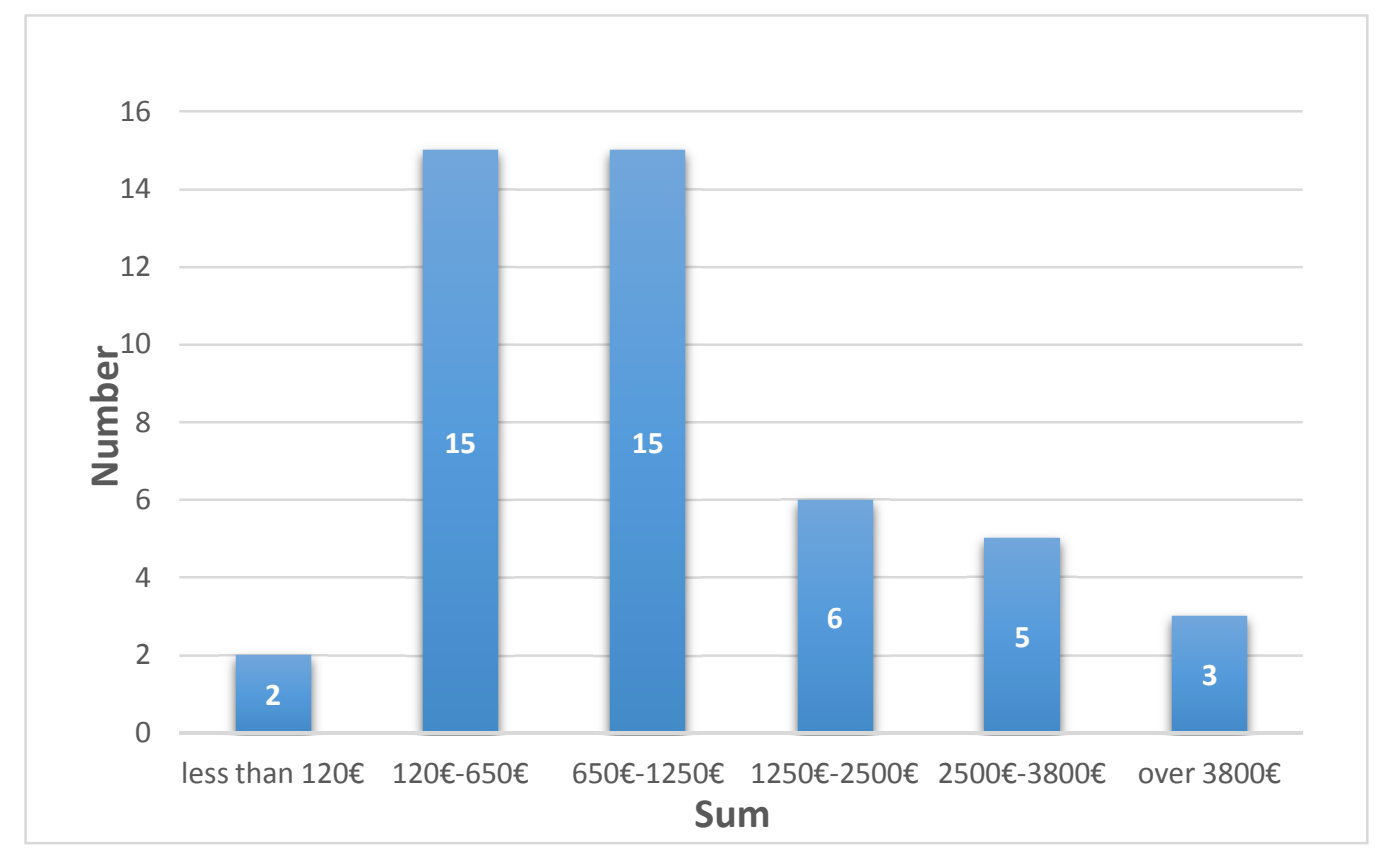

Figure 1. The distribution of self-funding of treatment in interviewed poor children with congenital heart disease (PCHD) families, $(n=46)$, in Euros.

There is valid data from the 46 cases that are available for the self-funded amounts in the interview. As can be seen from the above chart, most of the families paid a cost of $€ 120$ to $€ 1250$. These families were borrowing money from relatives and friends, so they had varying degrees of debt. The self-funding reflects a big stress for a single and small-income family. The Red Cross rescue not only helps many families avoid destructive damage to their finances, it also provides the psychological support in the form of hope and confidence to the family.

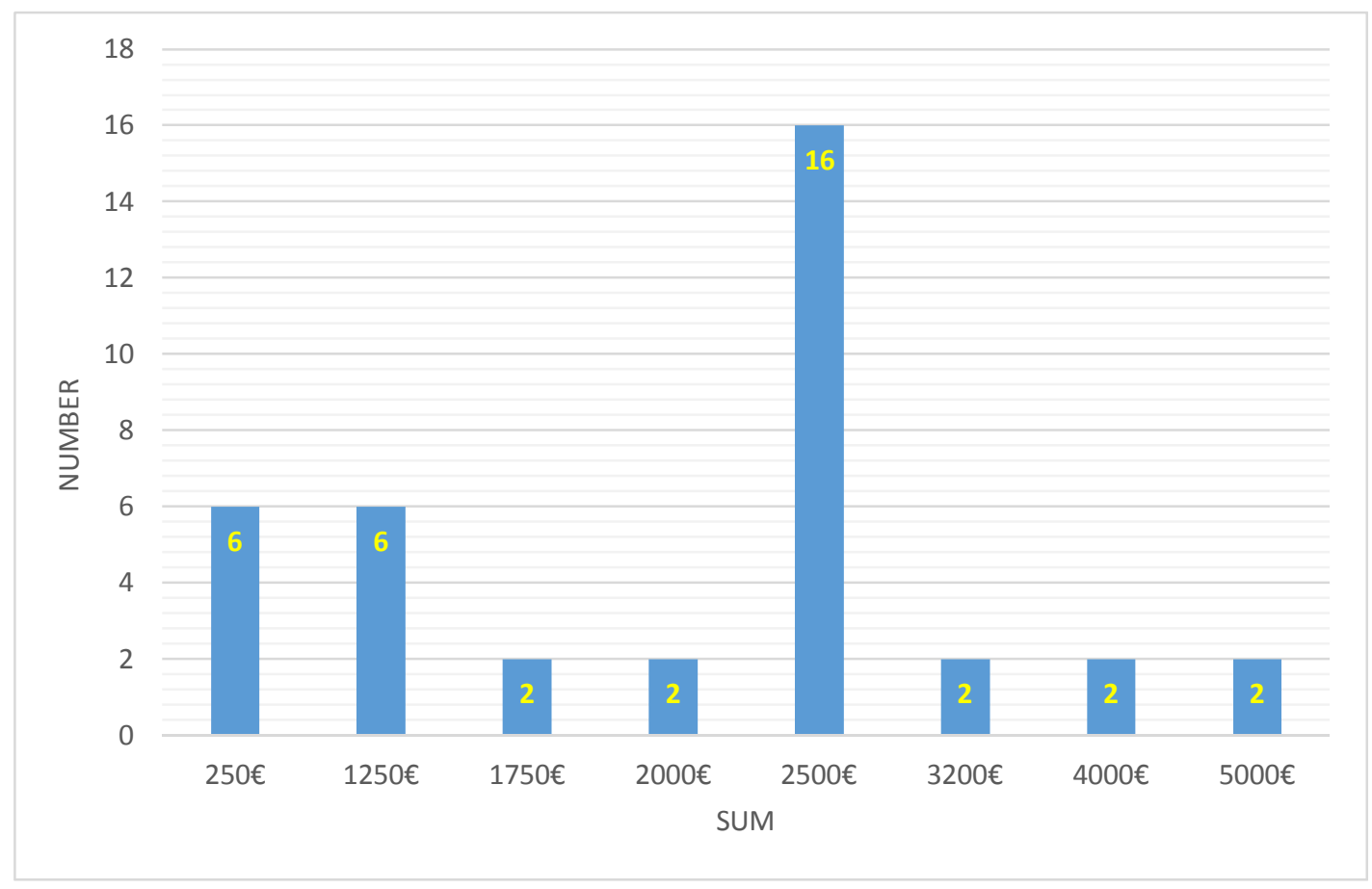

Figure 2. The distribution of Red Cross funding of treatment in interviewed PCHD families $(n=38)$. 
Effective data from 38 cases showed that the typical value of relief was $€ 2500$, accounting for $42.1 \%$ of the data, while the lowest relief amounts ( $€ 250$ and $€ 1250$ ) accounted for $15.8 \%$. Other relief amounts were more dispersed. The financial assistance is based on the principle of emergency priority, and more funding is allocated to complex heart disease. Interview data indicate that this differentiation of different levels of relief funding support is effective. During face-to-face interviews, a child's father talked about the timeliness of the Red Cross funding, and the lift to the entire family's spirits after the success of the child's surgery:

My son's illness was a combination of two serious diseases mixed together. I was very worried at the beginning. I blamed myself. I'm useless, can't earn enough money, my own body is not good, the child is more important than me. I decided to not cure myself, and to borrow money for my son's treatment, and then, sister Wang, who works in our sub-district office, came to my home and told me the country can help me. It was like a dream. The surgery was successful and our family did not spend too much money, we only spent one or two thousand yuan (€125-€250). Without the help of the Red Cross, that would have been a tough New Year. My son is the only son. Saving my son saved my family. [Shaking hand with the interviewer thankfully.]. (Interviewed father $L$ )

\subsection{Self-Reported Effect}

An important factor that reflects the effectiveness of the project is whether the child's physical condition is improved, which can be clearly obtained from the project evaluation data. Through the interviews with the project's cooperation hospital staff, we learned that the treatment success rate of children with congenital heart disease is generally more than $98.5 \%$. After interviewing the family face-to-face, we were able to classify the physical condition of the 66 children after receiving medical treatment in four categories.

Based on the child's current physical condition, only $4.5 \%$ of parents thought their children still had major health problems, so $95.5 \%$ of the children's heart treatment surgeries were regarded as successful, which is very close to the information that we obtained from hospital staff. The medical results of the poor children's congenital heart disease relief project are positive in most cases. A mother talked about her joy in the child's physical fitness after getting better:

Before surgery, my child (six years old) could not run or jump. I carried her every day when we went out because walking more would lead to shortness of breath. My daughter often got tired. I held her then, her head was bowed to my shoulder. [The mother begins sobbing]. I heard the sound of her heavy breathing, I was very distressed. When we went to the hospital, they first said it was pulmonary hypertension, then she received medicine, and surgery was arranged for the third day. The operation was successful, and now she is just the same as a normal child, besides a scar on the chest. Even swimming is no problem. (Interviewed mother B)

\subsection{Pros and Cons of the Program}

The advantages of the rescue program for children with congenital heart disease are as follows. First of all, with the continuous development of society and economy, the amount of aid is increasing, as can be clearly seen from Table 1. The funding of assistance has increased, both for the simple congenital heart disease and for all types of congenital heart disease. The amount of relief increased between 2010-2012, and a new mode of cost reimbursement and money assistance was implemented in 2013, in which the sources of relief funds were more diverse. Secondly, the ways for children to be rescued have become more appropriate. As far as rescue disease categories are concerned, the project could only help children with simple congenital heart disease at the beginning. However, since 2010, children with all types of congenital heart disease can apply for assistance in this PCHD project. So, for children who suffer from complex congenital heart disease, it has become more convenient to get 
help. Thirdly, the combination of theory and practice is improved. As can be seen from Table 1 , at the beginning of the rescue project, the project could only help the children with simple heart disease. In the process of cooperation with the hospital, staff of the Red Cross learnt more about the pathology of the congenital heart disease and the actual situation of the children. This indicates that the rescue coverage has become more extensive year by year, and additional competencies have been added to this field.

As far as the negative dimensions of the program, one is that the publicity of relief projects is not in place, and the popularity rate of related knowledge is low. There are advertisements on TV, the Internet, and the radio, but the advertising coverage is small, and the duration is short. From the data, only $12.1 \%$ of parents received information on the poor children's congenital heart disease relief project through media networks, television, newspapers, and so on. Only $24.2 \%$ of parents learned of the project through the doctor or hospital, and as many as $63.7 \%$ of parents obtained information about the project via "other" ways. As parents of poor families are often not highly educated, they may not be accustomed to using computers, and some families even cannot afford to buy a TV. Economic development in poverty-stricken areas tends to be more negative, and there is often a lack of information and knowledge. Due to insufficient awareness of the importance of prenatal examinations, especially in rural areas, giving birth to sick children is more common. In light of this, for regions with different economic levels, different methods of publicity should be taken in order to efficiently disseminate the advertising. Another shortcoming relates to the lack of transparency in the aid funding process. All of the parents knew that the funding they received came from the Red Cross, but they do not know the details of how much money the Red Cross has funded in total, how much money was funded through the hospital relief, and how the funding was organized. They only knew how much money they paid themselves and how much money they could get back via reimbursement. As such, some of the parents started to question whether the amount of money provided by the Red Cross was accurately reported. These negative characteristics of the project could be circumvented if the information was more transparent.

\section{Discussion}

As one of China's more mature nonprofit charitable organizations, the Red Cross Society of China is a favorable representative of Chinese social groups. Children in difficulty (CID) covers a lot of vulnerable groups of children, of which seriously ill children are just one part. In general, the Red Cross's assistance to poor children with congenital heart disease is a microcosm of the Chinese social organization's assistance to CID.

One of the important reasons for the emergence of CID is poverty (Bo et al. 2013). Due to poverty, some children may lose the best surgical opportunities. The poor children with congenital heart disease (PCHD) relief project helps some children out of this plight. In Table 2, we can see that the children who obtained help through the PCHD relief project recovered well after receiving medical treatment. Any child policy and child welfare in the final analysis are aimed at the healthy growth of children (Lu et al. 2005), while at the same time reducing the economic pressure and mental stress on poor families. Family harmony can bring social harmony, and of course, this kind of long-term effect needs time to become visible. When the national policy is not good enough to fully combat all of the plights of the people, and when welfare support is insufficient, nonprofit charitable organizations can play a complementary role, as they are the front-line service providers for CID assistance. At the same time, they also contribute to reducing the pressure on government services. The cooperation between nonprofit organizations and the government is a way to participate in the implementation of public policies. Nonprofit organizations have a sense of mission regarding building a better society. They may play a role as a guardian for vulnerable groups. For the country, NPOs have the function of subsidized public service (Huang and Gao 2010). 
Table 2. Children's physical condition.

\begin{tabular}{cccccc}
\hline Child Health Status & Number & Percentage & Effective Percentage & Cumulative Percentage \\
\hline \multirow{4}{*}{ Valid } & Back to normal & 48 & 72.7 & 73.8 & 73.8 \\
& Slightly inadequate & 11 & 16.7 & 16.9 & 90.8 \\
& Minor health problems & 3 & 4.5 & 4.6 & 95.4 \\
& Major health problems & 3 & 4.5 & 4.6 & 100.0 \\
& Total (excl. missing data) & 65 & 98.5 & 100.0 & \\
\hline \multirow{2}{*}{ Missing } & & 1 & 1.5 & & \\
\hline \multicolumn{6}{c}{} \\
& Total & 66 & 100.0 & & \\
\hline
\end{tabular}

CID relief in China has had a long-standing focus on welfare issues. In the beginning of this article, we talked about the concept of changes in CID relief, and how the ways of providing relief can be viewed as gradually changing due to the increased coverage of CID in need of treatment. With the development of economic globalization, the values of Chinese society are becoming more and more globalized, and social assistance has become more diverse. The provision of CID relief from a nonprofit charitable organization such as the Red Cross is a development that has been underway for a long time, and has always been in accordance with the practice of social conventions. Since 16 June 2016, the Chinese State Council promulgated the statement "Opinions of the State Council on Strengthening the Protection of Children in Difficulty" (China Government Website 2016). This statement explicitly proposes encouraging the participation of nonprofit charitable organizations in order to establish and improve the child security systems, especially for CID. The support of the government is undoubtedly a great boost for the advancement of children's welfare.

\section{Limitations of the Assessment Study}

There were 47 invalid questionnaires out of the 106 questionnaires among the telephone interview data, which to some extent affected the amount of effective data. The main reason for the failure of the sample in the telephone survey was changes to and loss of the parents' phone numbers. Most of the children funded by the project were living in suburban counties, some poor families were living in rural areas, and some children were living with their grandparents. Since their parents were working elsewhere, it was often hard to get in contact with them. This might have caused a selection problem, in that these families could have had a lower capacity for self-funding. However, the final number of 66 telephone interviews plus 10 face-to-face interviews still provides a relatively useful sample.

The project evaluation interview subjects only included project-related persons, which comprise Red Cross staff, hospital staff, and the guardians of assisted children. Thus, there is a lack of information from other relevant persons' assessments of the project (such as neighbors, school teachers, and other social citizens), so the social impact of the project cannot be comprehensively evaluated. Widening approaches in subsequent research may increase knowledge of the wider social impact of the project.

\section{Policy Recommendations}

For nonprofit charitable organizations to improve their provision of rescue activities for CID, there are things to consider:

The dissemination and promotion of rescues activities. If a nonprofit charitable organization wants to help CID through rescue projects, first of all, they should disseminate the related concepts of the project as far as possible. Taking the PCHD assistance project of the Red Cross in this article as an example, the idea that children must be examined for congenital heart disease should be transmitted to everyone, especially pregnant women. It is necessary to be aware of the dangers of congenital heart disease. Also, the nonprofit charitable organizations should disseminate content about the work that they do. This is beneficial to the follow-up work, in order to improve the transparency of the project process and ensure the adequate use of funds. In order to facilitate improved understanding among the project recipients as to the nature of rescue organizations, they should conduct publicity and promotion efforts through public service advertising, short public films, and other promotional 
methods. The information that is given needs to be adapted to local conditions. For the majority of the population, Internet (computer and cellphone), television, and radio are effective, but for remote areas, people share new information by word-of-mouth. Relevant staff ${ }^{3}$ should promote time and a frequency of contact with people who live in remote areas. All of this is facilitated by the full support of the government.

Establish an online information management platform. The establishment of an online management platform needs to be considered as soon as possible, in order to create functioning archives for case files documenting the physical condition, family situation, surgical procedure, postoperative feedback, etc. of each child. This could optimize the process, eliminate cumbersome information reporting, and improve work efficiency. The orderly management of the file would help the nonprofit charitable organizations grasp the local project dynamics, ensure real-time monitoring, and make it easier to achieve timely adjustments. This could be done by selecting one charity organization as a pilot in which an online management platform can be constructed and tested. As soon as this platform has become mature and functions well, it could be extended to the whole province.

Strengthen management and supervision. Developing a third-party supervision agency outside the nonprofit charitable organizations' working system is important. This agency can periodically assess the work results of the organization to ensure the rational use of funds. In the supervision and evaluation work, nonprofit charitable organizations should pay special attention to transparency, which is good for public participation in supervision, and would reflect an effort to form social credibility in order to provide more favorable relief.

\section{Conclusions}

Nonprofit charitable organizations play a complementary role in government assistance for CID. They provide positive support in helping poor families, and at the same time reduce the burden of government services. Readers can learn from the program presented in this study about the ways that charity organizations such as the Red Cross help CID, and the rescue effect of their work. Diversification of relief is important within the CID relief system, and the closeness of the cooperation between institutions is directly related to the effectiveness of the rescue result. Ideally, harmonious relationships between state and regional governments, charities, local communities, and families help children grow up healthy.

This study hopes to convey a message to the community through the results of an assessment of a particular NPO program. The study shows that NPO assistance to CID is very necessary and cannot be ignored. However, CID relief is not just a matter of government and social organization; ordinary people also need to be involved to support these nonprofit charitable organizations and enable them to provide better assistance to those in need. This can be realized, for example, by more people engaging in voluntary work, and more people being willing to donate money to the NPOs.

Author Contributions: Y.D. was co-responsible for the study design, data collection, preliminary analyses of the study and drafting of the article. L.N. assisted with the final analyses and drafting of the article.

Acknowledgments: The project was supported by the L Red Cross. Thanks for the help of Professor Baogui $\mathrm{Du}$ and very appreciate the guidance of the project leader, Professor Jian Li. Thanks a lot for the big support of Xiaochen Li who works together at the initial projects.

Conflicts of Interest: The authors declare no conflicts of interest.

3 For example, the staff of nonprofit charitable organizations, the local Women' Federation and the village committee, etc. 


\section{References}

Bo, Wen-Yong, Guang-Fen Huang, and Fang Qi. 2013. Research on rescue strategies for difficult children under the perspective of social management innovation-From the perspective of child welfare theory. The Journal of Yunnan Administration College 2: 137-140. [CrossRef]

Chen, Lu-Nan. 2012. The concept and guarantee principle of Children in difficulty. Social Welfare 7: 27-28.

Chen, Yan. 2008. Comparative analysis of child welfare system between China and the United States. Xiang Chao 5: 22-23.

China Government Website. 2016. Illustration-Opinions of the State Council on Strengthening the Protection of Children in Difficulty. Available online: http:/ / www.gov.cn/xinwen/201606/16/content_5082870.htm (accessed on 16 June 2016).

China Youth Research Center. 2006. Civil children's relief organization survey task group. Civilian Children's Relief Organization Survey Report-Current Situation, Problems and Countermeasures. China Youth Study 5: 14-19. [CrossRef]

Chinese Children's Welfare Policy Research Group. 2016. Building Protective Child Welfare System. Beijing: China Philanthropy Research Institute, NNICEF.

Confucius. About 540 BC-400 BC. Analects of Confucius, the First Article"Xue-er". Available online: https://baike.baidu.com/item/\%E8\%AE\%BA\%E8\%AF\%AD\%C2\%B7\%E5\%AD\%A6\%E8\%80\%8C\%E7\%A $\mathrm{F} \% 87 / 8177005$ ?fr=aladdin (accessed on 12 June 2018).

Decree of the State Council of the People's Republic of China. 2004. Foundation Management Ordinance, Chapter One. Available online: http:/ / www.gov.cn/zhengce/content/2008-03/28/content_6434.htm (accessed on 28 March 2008).

Huang, Zhi-Xiong, and Jian-Guo Gao. 2010. Social Welfare Research, 2nd ed. Beijing: Chinese Social Press, p. 108. ISBN 9787508732886.

Liu, Ji-Tong. 2005. The Theoretical Framework and the Policy Framework of Children's Welfare in the Period of Social Transformation. China Youth Study 7: 29-34. [CrossRef]

Liu, Jun. 2010. Realtions between NOPS and Government in the Perspective of Funding Resources. Journal of Guangxi University (Philosophy and Social Science) 3: 24-29. [CrossRef]

Li, Yue-E, Xiao-Ou Man, and Zhen Li. 2012. The Advantages of Religious Non-profit Organizations Participating in the American Philanthropy. Learned Society 5: 8-12.

Lu, Shi-Zhen, Zhao-Peng Wei, and Wei Hu. 2005. An Introduction to China's Children's Policy. Beijing: Social Sciences Academic Press, p. 164. ISBN 9787801907820.

Ministry of Health P.R. China. 2012. Report on the Prevention and Control of Birth Defects in China. Available online: http:/ / www.gov.cn/fwxx/jk/2012-09/13/content_2223565.htm (accessed on 13 September 2012).

National Board of Health and Welfare. 2012. Child Welfare in a State of Change. Final Report from the BBIC Project; Stockholm: Socialstyrelsen.

National People's Congress Standing Committee Member. 2005. Law of the People's Republic of China on Red Cross, chapter one. Available online: http:/ / www.gov.cn/banshi/2005-08/01/content_18932.htm (accessed on 1 August 2005).

Shi, Guo-liang. 2012. A New Form of Cooperation between Governments and Non-profit Organizations Abroad. Journal of Sichuan Normal University (Social Sciences Edition) 3: 19-29. [CrossRef]

Smith, David Horton, Robert A Stebbins, and Michael A. Dover. 2006. A Dictionary of Nonprofit Terms and Concepts. Bloomington: Indiana University Press, pp. 156-57.

State Council. 2016. Opinions of the State Council on Strengthening the Work of Rescuing Children in Difficulty. Available online: http://www.gov.cn/zhengce/content/2016-06/16/content_5082800.htm (accessed on 16 June 2016).

State Council. 1992. Notifications of the State Council on the Arrival of "Outline of the Plan for the Development of China's Children in 90s". National Document [1992] No. 9, p. 78. 
World Health Organization, and Regional Office for South-East Asia. 2009. World Health Organization Health Financing Strategy for the Asia Pacific Region (2010-2015). Geneva: WHO, vol. 49, pp. 337-44.

You, Jia-Li. 2014. Regulatory mechanisms for Nonprofit and charitable organizations in Switzerland. China Institutional Reform and Management 2: 89-94. ISSN 2095-1507. 